\title{
Atividade e população microbiana envolvida nas transformações do enxofre em solos com diferentes vegetações ${ }^{(1)}$
}

\author{
Cristiane Rêgo Oliveira Pinto(2) e Ely Nahas $^{(3)}$
}

\begin{abstract}
Resumo - O objetivo deste trabalho foi determinar as populações microbianas e suas atividades envolvidas no ciclo do $\mathrm{S}$, de solos virgem e cultivado, e as suas relações com as diferentes frações de $\mathrm{S}$ no solo. Das populações de microrganismos pesquisados, apenas foram encontradas as bactérias autótrofas oxidantes de $\mathrm{S}^{0} \mathrm{em} \mathrm{pH} \mathrm{5,0}$ e as heterótrofas oxidantes de tiossulfato, que representaram menos de $0,1 \%$ das bactérias totais. A média das bactérias autótrofas foi o dobro das heterótrofas. As maiores contagens de bactérias totais, autótrofas e heterótrofas foram encontradas nos solos com milho, de pastagem e de floresta integrada, respectivamente. A atividade da arilsulfatase foi maior em solo de floresta integrada e a da rodanase em solo de pastagem. A arilsulfatase correlacionou com as populações de heterotróficos, C orgânico, S total, S orgânico, matéria orgânica e umidade do solo; e a rodanase com C orgânico, S total e S orgânico. Os teores de S orgânico e sulfato foram de 94-98\% e 2-6\% do S total, respectivamente. Os maiores teores de $\mathrm{S}$ total e orgânico foram encontrados no solo de floresta integrada. O S total correlacionou com o S orgânico, umidade e matéria orgânica, e o S orgânico com a matéria orgânica.
\end{abstract}

Termos para indexação: bactéria, oxidação, arilsulfatase, rodanase.

\section{Activity and microbial populations involved in sulfur cycling in soils with different vegetations}

\begin{abstract}
The objective of this work was to assess the microbial populations and its activities involved in the $\mathrm{S}$ cycle, of virgin and cultivated soils, and its relationships with the different fractions of $\mathrm{S}$ in the soil. The influence of soils with different vegetations on microbiological and biochemical characteristics was investigated. Out of the different populations of microorganisms examined, only the $\mathrm{S}^{0}$-oxidizing autotrophic bacteria and thiosulfate-oxidizing heterotrophs that represented less than $0.1 \%$ of the total bacteria were found. The average of autotrophs was double that of the heterotrophs. The highest counts of total bacteria, autotrophic and heterotrophic microorganisms were found in corn, pasture and forest soils, respectively. Arylsulfatase activity was greater in forest soil, and rhodanese activity in pasture soil. Arylsulfatase correlated with heterotrophic populations, organic C, total S, organic S, organic matter and soil moisture; and rhodanese with organic $\mathrm{C}$, total $\mathrm{S}$, and organic $\mathrm{S}$. The contents of organic $\mathrm{S}$ and sulfate were of $94-98 \%$ and $2-6 \%$ of total S, respectively. The major content of total S and organic S was found in the forest soil. Total S correlated significantly with organic S, moisture and organic matter and organic $\mathrm{S}$ with organic matter.
\end{abstract}

Index terms: bacteria, oxidation, arylsulfatase, rhodanese.

(1) Aceito para publicação em 26 de julho de 2002.

Extraído da dissertação de mestrado apresentada pelo primeiro autor à Universidade Estadual Paulista (Unesp), Faculdade de Ciências Agrárias e Veterinárias (FCAV), Jaboticabal, SP. Financiado pela Fapesp.

(2) Rua C, Quadra 11, casa 33, Bairro Maranhão Novo, CEP 65061-070 São Luiz, MA.

(3) Unesp, FCAV, Dep. de Produção Vegetal, CEP 14884-900 Jaboticabal, SP. Bolsista do CNPq. E-mail: enahas@fcav.unesp.br

\section{Introdução}

O S é um dos elementos mais abundantes na terra após o C e o nitrogênio. É essencial para os organismos vivos, por fazer parte da constituição de proteínas e outros compostos orgânicos, e por ser fonte de energia para as bactérias litotróficas e aceptor de elétrons oriundos do metabolismo respiratório das bactérias redutoras de sulfato (Tate, 1995). Além de 
os teores de S disponível serem bastante baixos, principalmente nos solos tropicais, e não satisfazerem as necessidades das plantas (Castellano \& Dick, 1990), alterações na condução das práticas agrícolas têm concorrido para diminuir a quantidade de $\mathrm{S}$ disponível (Eriksen et al., 1995). Dessa forma, há necessidade de se aplicar fertilizantes que contenham $S$ na forma elementar ou superfosfato simples.

Em sistemas de culturas de plantas permanentes, não usualmente fertilizadas, como de espécies arbóreas e pastagens, as necessidades de $\mathrm{S}$ para o desenvolvimento das plantas devem provir da reciclagem da matéria orgânica depositada no solo, por meio de transformações microbianas ou químicas que produzem sulfato disponível que pode ser absorvido pelas plantas.

O S orgânico do solo pode existir como ésteres de sulfato ou ligado ao C (Shan et al., 1997), e as sulfatases são as enzimas responsáveis pela hidrólise desses ésteres para sulfato (Klose \& Tabatabai, 1999). Dentre essas enzimas, as arilsulfatases têm sido detectadas em inúmeros solos (Nahas et al., 1997). As rodanases, que catalisam a formação de tiocianato de tiossulfato e cianeto, dois compostos produzidos no solo (Nor \& Tabatabai, 1975) na oxidação do $\mathrm{S}$, têm sido pouco estudadas.

Diferentes microrganismos participam da transformação do S inorgânico, como as bactérias do gênero Thiobacillus, consideradas de maior importância na oxidação de compostos reduzidos do $\mathrm{S}$ no solo (Lens et al., 2000). Vários microrganismos heterotróficos também oxidam o $\mathrm{S}$ elementar a tiossulfato, tetrationato e pentationato, resultando como produto final o sulfato no solo (Kelly et al., 1997).

O objetivo deste trabalho foi determinar as populações microbianas e suas atividades envolvidas no ciclo do $\mathrm{S}$ de solos virgem e cultivado e suas relações com as diferentes frações de $\mathrm{S}$ no solo.

\section{Material e Métodos}

Amostras de solos foram coletadas $(0-20 \mathrm{~cm})$ de cinco áreas da Estação Experimental da Unesp (Jaboticabal, SP) (Tabela 1). As amostras coletadas de solo cultivado ou do horizonte A dos solos de florestas e de pasto foram transportadas imediatamente para o laboratório e peneiradas em peneiras de $2 \mathrm{~mm}$ de malha. Parte delas foi secada ao ar por 24 horas, para as análises químicas, e a outra foi armazenada à temperatura de $4^{\circ} \mathrm{C}$ em sacos de polietileno até o momento da determinação das contagens bacterianas e da atividade microbiana.

As contagens do número mais provável (NMP) foram feitas em microplacas com 24 poços. Amostras de $10 \mathrm{~g}$ do solo úmido foram transferidas a erlenmeyer de $250 \mathrm{~mL}$ contendo $95 \mathrm{~mL}$ de solução de pirofosfato de sódio $0,1 \%$ $(\mathrm{p} / \mathrm{v})$ autoclavado. Após agitação por 30 minutos em agitador horizontal e preparação de diluições decimais de $10^{-2}$ a $10^{-9}$, foram tomadas amostras $(0,3 \mathrm{~mL})$ dessas diluições e transferidas para microplacas esterilizadas contendo $2,7 \mathrm{~mL}$ do meio de cultura apropriado por poço. As microplacas foram guardadas em sacos de polietileno contendo algodão umedecido em água destilada, para manter a umidade, e incubadas a $25^{\circ} \mathrm{C}$.

As bactérias totais foram quantificadas em meio Bunt \& Rovira (1955), incubando-se as microplacas por 24 horas. Os poços foram observados de forma a detectar presença ou ausência de turvação causada pelo crescimento bacteriano. Contagens de microrganismos autótrofos fo-

Tabela 1. Características químicas e granulométricas de quatro Latossolos Vermelhos (LV) e de um Nitossolo Vermelho (NV).

\begin{tabular}{|c|c|c|c|c|c|}
\hline Características & $\begin{array}{c}\text { LV } \\
\text { Eutrófico } \\
\text { (floresta isolada) }^{(1)} \\
\end{array}$ & $\begin{array}{c}\text { LV } \\
\text { eutroférrico } \\
\text { (floresta integrada) }^{(1)}\end{array}$ & $\begin{array}{c}\text { LV } \\
\text { distrófico } \\
\text { (milho) } \\
\end{array}$ & $\begin{array}{c}\text { LV } \\
\text { distrófico } \\
\text { (eucalipto) }\end{array}$ & $\begin{array}{c}\text { NV } \\
\text { eutroférrico } \\
\text { (pasto) }\end{array}$ \\
\hline Matéria orgânica (\%) & 3,1 & 4,3 & 1,5 & 1,8 & 2,8 \\
\hline $\mathrm{P}\left(\mathrm{mg} / \mathrm{dm}^{3}\right)$ & 12,0 & 37,0 & 52,0 & 7,0 & 14,0 \\
\hline $\mathrm{K}\left(\mathrm{mmol}_{\mathrm{c}} / \mathrm{dm}^{3}\right)$ & 3,6 & 3,3 & 1,8 & 1,8 & 5,1 \\
\hline $\mathrm{Ca}\left(\mathrm{mmol}_{\mathrm{d}} / \mathrm{dm}^{3}\right)$ & 79,0 & 88,0 & 24,0 & 4,0 & 37,0 \\
\hline $\mathrm{H}+\mathrm{Al}\left(\mathrm{mmol}_{\mathrm{c}} / \mathrm{dm}^{3}\right)$ & 18,0 & 25,0 & 16,0 & 58,0 & 47,0 \\
\hline $\mathrm{pH}\left(\mathrm{CaCl}_{2}\right)$ & 6,1 & 5,9 & 5,7 & 4,0 & 5,1 \\
\hline Argila (\%) & 43,0 & 36,0 & 30,0 & 26,0 & 43,0 \\
\hline Silte $(\%)$ & 17,0 & 20,0 & 4,0 & 7,0 & 30,0 \\
\hline Areia (\%) & 40,0 & 44,0 & 66,0 & 67,0 & 27,0 \\
\hline Umidade $(\%)$ & 18,0 & 23,2 & 10,0 & 11,2 & 18,2 \\
\hline
\end{tabular}

${ }^{(1)}$ A floresta isolada (remanescente isolado) e a floresta integrada (remanescente integrado à mata ciliar) são classificadas como floresta tropical latifoliada semidescídua 
ram feitas utilizando-se o meio ATCC 125 (Lawrence \& Germida, 1988) contendo $\mathrm{S}^{0}$ ou tiossulfato, $\mathrm{pH}$ 5,0 ou 7,0 e um indicador para mostrar a diminuição do $\mathrm{pH}$ resultante da oxidação das fontes de enxofre. As microplacas foram incubadas por oito semanas e verificadas semanalmente quanto aos resultados positivos. TSB (Trypticase-soy-broth) contendo $\mathrm{S}^{0}$ ou tiossulfato (Lawrence \& Germida, 1988) foi utilizado na contagem de populações de microrganismos heterotróficos após incubação das placas por sete dias. Resultados positivos foram verificados pela detecção dos produtos finais da oxidação de $\mathrm{S}$, pelo método de Nor \& Tabatabai (1975)

A atividade da arilsulfatase foi determinada pela utilização de p-nitrofenil sulfato como substrato (Tabatabai \& Bremner, 1970). Uma unidade de atividade correspondeu à quantidade de enzima que produziu $1,0 \mu \mathrm{g}$ de p-nitrofenol por $1 \mathrm{~g}$ de solo seco, por hora. A atividade da rodanase foi determinada conforme o método de Tabatabai \& Singh (1976). Uma unidade da enzima foi definida como a quantidade de $1 \mathrm{nmol}$ de tiocianato produzido a partir de $1 \mathrm{~g}$ de solo seco, por hora.

$\mathrm{O}$ carbono da biomassa microbiana (C-biomassa) foi medido pelo método de Vance et al. (1987). Foi utilizado o fator de conversão de 2,64 para converter C extraído em biomassa. O C orgânico do solo foi estimado segundo Sims \& Haby (1971). Sulfato solúvel e $\mathrm{S}$ total foram determinados segundo Bardsley \& Lancaster (1965), e o S orgânico foi calculado como a diferença entre o $S$ total e o sulfato. $\mathrm{O}$ pH do solo foi determinado na relação 1:1 de solo e $0,01 \mathrm{M} \mathrm{CaCl}_{2}$.

O delineamento utilizado foi o inteiramente casualizado, com quatro repetições, e os dados analisados pelo programa ESTAT. Os resultados das contagens microbianas foram transformados em log. As médias foram comparadas pelo teste de Tukey a $5 \%$ de probabilidade. Análises de correlação simples (r) foram feitas para estimar as relações entre as propriedades dos solos determinadas.

\section{Resultados e Discussão}

O número de bactérias totais no solo com milho foi 2 a 35 vezes maior que o dos outros solos, mas apenas diferiu significativamente dos solos de floresta isolada e de eucalipto (Tabela 2). O estímulo das bactérias totais em solo com milho pode ser atribuído ao aumento da disponibilidade de nutrientes resultantes do aumento da velocidade de degradação da matéria orgânica, em razão das práticas de cultivo a que o solo foi submetido. A diminuição do conteúdo de matéria orgânica observada no solo com milho em relação aos outros solos confirma esta afirmação (Tabela 1).

Das diferentes populações de microrganismos investigados, as bactérias autótrofas oxidantes de tiossulfato nos pH 5,0 e 7,0 e de $\mathrm{S}$ elementar em $\mathrm{pH}$ 7,0 e os microrganismos heterotróficos oxidantes de $\mathrm{S}$ elementar não foram encontrados. As bactérias autótrofas oxidantes de $\mathrm{S}$ elementar ( $\mathrm{S}^{0}$-oxidantes) em pH 5,0 e as heterótrofas oxidantes de tiossulfato $\left(\mathrm{S}_{2} \mathrm{O}_{3}{ }^{2-}\right.$-oxidantes) foram as únicas populações encontradas e corresponderam a menos de $0,1 \%$ do total de bactérias (Tabela 2). Em termos absolutos, essa pequena fração foi similar à encontrada por Chapman (1990) em solos de clima temperado, mas foi superada em cinco solos agrícolas de Saskatchewan em que a população de microrganismos heterotróficos $\mathrm{S}^{0}$-oxidantes variou de $0,0001 \%$ a $16,0 \%$ em relação ao total de heterótrofos (Lawrence \& Germida, 1988).

As bactérias autótrofas $\mathrm{S}^{0}$-oxidantes aumentaram no solo sob pastagem $\left(88,9 \times 10^{5} / \mathrm{g}\right.$ de solo seco) em relação aos demais solos; contudo, esta contagem só foi diferente da observada no solo com milho, que apresentou os menores valores. A população de microrganismos heterotróficos $\mathrm{S}_{2} \mathrm{O}_{3}{ }^{2-}$-oxidantes foi estimulada no solo de floresta integrada e aumentou cerca de cinco vezes em relação aos demais solos. Nenhuma tendência foi verificada em relação à distribuição das populações de microrganismos oxidantes de $\mathrm{S}$ nos diferentes solos. A média das populações de autotróficos foi o dobro da dos heterotróficos e diferente dos resultados de Chapman (1990) e Lawrence \& Germida (1991), que encontraram maior população de heterótrofos oxidantes de $\mathrm{S}$ que os autotróficos em solos agrícolas. A falta de uma fonte de $\mathrm{C}$ disponível pode ter limitado o

Tabela 2. Número mais provável de bactérias totais e microrganismos oxidantes de enxofre nos cinco solos ${ }^{(1)}$.

\begin{tabular}{lccc}
\hline Vegetação & $\begin{array}{c}\text { Bactérias } \\
\text { totais } \\
\left(\times 10^{8}\right)\end{array}$ & $\begin{array}{c}\text { Autotróficos } \\
\mathrm{S}^{0} \text {-oxidantes } \\
\left(\times 10^{5}\right)\end{array}$ & $\begin{array}{c}\text { Heterotróficos } \\
\mathrm{S}_{2} \mathrm{O}_{3}{ }^{2-} \text {-oxidantes } \\
\left(\times 10^{5}\right)\end{array}$ \\
\hline Floresta isolada & $5,6 \mathrm{~b}$ & $32,3 \mathrm{ab}$ & $12,8 \mathrm{~b}$ \\
Floresta integrada & $28,7 \mathrm{ab}$ & $57,5 \mathrm{a}$ & $68,8 \mathrm{a}$ \\
Milho & $194,9 \mathrm{a}$ & $5,6 \mathrm{~b}$ & $13,4 \mathrm{~b}$ \\
Eucalipto & $19,2 \mathrm{~b}$ & $59,9 \mathrm{a}$ & $13,8 \mathrm{~b}$ \\
Pastagem & $77,5 \mathrm{ab}$ & $88,9 \mathrm{a}$ & $13,2 \mathrm{~b}$ \\
\hline $\mathrm{CV}(\%)$ & 6,41 & 5,90 & 5,10 \\
\hline
\end{tabular}

${ }^{(1)}$ Em cada coluna, médias seguidas da mesma letra não diferem entre si a $5 \%$ de probabilidade pelo teste de Tukey. 
crescimento dos heterotróficos $\mathrm{S}_{2} \mathrm{O}_{3}{ }^{2-}$-oxidantes ou o $\mathrm{pH}$ pode ter favorecido os autótrofos $\mathrm{S}^{0}$-oxidantes. Vitolins \& Swaby (1969) sugeriram que, em solos com pH abaixo de 5,0, a oxidação do $\mathrm{S}$ foi causada pela atividade do Thiobacillus thioxidans. Confirmando esses resultados, os solos de eucalipto e de pastagem apresentaram menor valor de $\mathrm{pH}$ (Tabela 1) e aumento da população bacteriana $\mathrm{S}^{0}$-oxidante em relação aos demais solos (Tabela 2).

A população heterotrófica $\mathrm{S}_{2} \mathrm{O}_{3}{ }^{2-}$-oxidante correlacionou-se significativamente com o C orgânico $\left(R=0,39^{*}\right)$, então o maior aumento desses microrganismos no solo de floresta integrada comprova o efeito da fonte de $\mathrm{C}$ sobre os heterotróficos uma vez que o conteúdo de matéria orgânica foi maior nesse solo do que nos demais estudados (Tabela 1).

O C-biomassa e o C orgânico foram determinados para se estabelecer suas relações com os diversos parâmetros estudados. Enquanto o C-biomassa foi maior no solo com milho e menor no solo de floresta integrada, o teor de C orgânico foi maior no solo de floresta integrada e menor no com milho (Tabela 3).

A variação dos teores de $S$ total e orgânico apresentou a mesma tendência nos solos estudados, tendo sido encontrados os maiores teores no solo de floresta integrada, que foram significativamente superiores aos demais (Tabela 3). O conteúdo de sulfato variou de 3,21 a 7,39 $\mu \mathrm{g} / \mathrm{g}$ de solo e, no solo de floresta isolada, correspondeu a cerca de duas vezes aos teores observados nos outros solos. O conteúdo das diferentes formas de $\mathrm{S}$ nos solos estudados foi semelhante aos teores encontrados em solos da Dinamarca (Ganeshamurthy \& Nielsen, 1990), Saskatchewan (Gupta et al., 1993; Farrel et al., 1994)e norte da Escócia (Chapman, 1997). O S orgânico correspondeu a $95 \%$ do $\mathrm{S}$ total, confirmando Tabatabai
\& Bremner (1972). A proporção de sulfato em relação ao $\mathrm{S}$ total foi baixa, $3 \%$, quando comparada com as médias relatadas em solos de Gana, de 6\%, (Acquaye \& Kang, 1987) e Iowa, 9\%, (Tabatabai \& Bremner, 1972). No entanto, a principal fonte de S para as plantas foi proveniente da mineralização da matéria orgânica, como mostra a forte correlação entre $S$ total e $S$ orgânico e o conteúdo de matéria orgânica do solo $\left(\mathrm{R}=0,95^{* *}\right)$. Além disso, foi obtida correlação positiva entre o teor de $\mathrm{C}$ orgânico e os teores de $\mathrm{S}$ total $\left(\mathrm{R}=0,69^{* *}\right)$ e $\mathrm{S}$ orgânico $\left(\mathrm{R}=0,68^{* *}\right)$. Os maiores conteúdos de $\mathrm{S}$ total e $\mathrm{S}$ orgânico foram encontrados nos solos de floresta integrada, pastagem e floresta isolada, confirmando Acquaye \& Kang (1987).

A atividade da arilsulfatase no solo de floresta integrada foi de 37,02 $\mu \mathrm{g}$ de p-nitrofenol/g de solo seco/h e diminuiu significativamente em relação aos demais solos, na seguinte ordem: floresta integrada > floresta isolada $>$ eucalipto $>$ pastagem $>$ milho (Tabela 4). No solo com milho, a atividade foi extremamente baixa $(0,15 \mu \mathrm{g}$ de $\mathrm{p}$-nitrofenol/g de solo seco/h) correspondendo a 152 vezes menos que a máxima observada. A atividade da arilsulfatase foi comparável aos resultados encontrados em solos de Iowa, que variaram de 2 a $57 \mu \mathrm{g} / \mathrm{g}$ de solo (Tabatabai \& Bremner, 1970), porém foi superior aos obtidos por Ganeshamurthy \& Nielsen (1990), que variaram de 3-4 $\mu \mathrm{g} / \mathrm{g}$ de solo. Maior amplitude da atividade, de 14 a 770 e de 8 a 829, foi encontrada nos solos de Saskatchewan (Gupta et al., 1993; Farrel et al., 1994). É possível que nesses solos a alta atividade tenha sido decorrente do teor de $\mathrm{C}$ orgânico, que foi pelo menos três vezes maior que a encontrada nos solos do presente trabalho. A produção da arilsulfatase foi dependente da população microbiana heterotrófica $\mathrm{S}_{2} \mathrm{O}_{3}{ }^{2-}$-oxidante $\left(\mathrm{R}=0,47^{* * *}\right)$, corroborando Lawrence

Tabela 3. Conteúdos de carbono orgânico, carbono da biomassa microbiana (C-biomassa), enxofre total, enxofre orgânico e sulfato nos cinco solos sob diferentes vegetações ${ }^{(1)}$.

\begin{tabular}{|c|c|c|c|c|c|}
\hline Vegetação & $\begin{array}{c}\text { Carbono orgânico } \\
\text { (mg C/g de } \\
\text { solo seco) }\end{array}$ & $\begin{array}{l}\text { C-biomassa } \\
(\mu \mathrm{g} \mathrm{C/g} \mathrm{de} \\
\text { solo seco) }\end{array}$ & $\begin{array}{c}\text { Enxofre total } \\
(\mu \mathrm{g} \mathrm{S} / \mathrm{g} \\
\text { de solo seco) }\end{array}$ & $\begin{array}{c}\text { Enxofre orgânico } \\
(\mu \mathrm{g} \mathrm{S} / \mathrm{g} \mathrm{de} \\
\text { solo seco })\end{array}$ & $\begin{array}{c}\text { Sulfato } \\
(\mu \mathrm{g} \mathrm{S} / \mathrm{g} \text { de } \\
\text { solo seco) }\end{array}$ \\
\hline Floresta isolada & $7,79 \mathrm{~b}$ & $263,07 b$ & $167,09 \mathrm{~b}$ & $159,70 \mathrm{~b}$ & $7,39 \mathrm{a}$ \\
\hline Floresta integrada & $10,11 \mathrm{a}$ & $111,09 \mathrm{~d}$ & $229,89 a$ & $226,24 a$ & $3,65 b$ \\
\hline Milho & $3,57 \mathrm{c}$ & $379,27 \mathrm{a}$ & $74,85 \mathrm{c}$ & $70,97 \mathrm{c}$ & $3,88 b$ \\
\hline Eucalipto & $3,65 \mathrm{c}$ & $127,54 \mathrm{~cd}$ & $70,99 \mathrm{c}$ & $66,76 \mathrm{c}$ & $4,24 \mathrm{~b}$ \\
\hline Pasto & $3,67 \mathrm{c}$ & $229,25 \mathrm{bc}$ & $188,08 \mathrm{~b}$ & $184,86 \mathrm{~b}$ & $3,21 \mathrm{~b}$ \\
\hline $\mathrm{CV}(\%)$ & 22,83 & 29,14 & 10,44 & 10,95 & 13,62 \\
\hline
\end{tabular}

(1)Em cada coluna, médias seguidas da mesma letra não diferem entre si a 5\% de probabilidade pelo teste de Tukey. 
\& Germida (1991), mas não da população bacteriana total nem das bactérias autótrofas, em que não foi encontrada correlação significativa. Além disso, a correlação significativa entre a atividade da arilsulfatase e o teor de $\mathrm{C}$ orgânico total $\left(\mathrm{R}=0,82^{* * *}\right)$ sugere que os microrganismos produtores dessa enzima necessitam de uma fonte de $\mathrm{C}$ e de energia. Também, Ross et al. (1995) relataram que a variação da atividade da arilsulfatase deveu-se à variação do C total.

Dodgson et al. (1982) relataram que a produção da arilsulfatase foi controlada pelo conteúdo de $\mathrm{C} \mathrm{e}$ enxofre. Dessa forma, os teores de S orgânico podem ser importantes na atividade da enzima que hidrolisaria substratos S-orgânicos para produzir sulfato. De fato, foi encontrada correlação significativa entre a atividade da enzima e o teor de S orgânico $\left(\mathrm{R}=0,74^{* *}\right)$ ou total $\left(\mathrm{R}=0,74^{* *}\right)$, confirmando, assim, Gupta et al. (1993).

Não foi encontrada correlação significativa entre a atividade da arilsulfatase e o conteúdo de sulfato, possivelmente em decorrência dos baixos conteúdos de sulfato no solo para inibir a atividade dessa enzima (Kang \& Freeman, 1998), ou porque ela não é inibida por sulfato, mas por sulfito (Tabatabai \& Bremner, 1970). Contudo, há relatos contraditórios a esse respeito. Enquanto Gupta et al. (1993) observaram correlação fraca entre a atividade da arilsulfatase e sulfato, Farrel et al. (1994) não obtiveram correlação significativa.

A atividade da rodanase variou de 154,24 a 1.747,07 nmoles de SCN-/g de solo seco/h; aumentou significativamente nos solos de pastagem e de floresta integrada em relação à dos demais solos, e nos solos com milho e com eucalipto foi cerca de 11

Tabela 4. Atividades da arilsulfatase e da rodanase nos cinco solos ${ }^{(1)}$.

\begin{tabular}{lcc}
\hline Vegetação & $\begin{array}{c}\text { Arilsulfatase }(\mu \mathrm{g} \text { de } \\
\text { p-nitrofenol/g de } \\
\text { solo seco/h) }\end{array}$ & $\begin{array}{c}\text { Rodanase } \\
\text { (nmoles de } \mathrm{SCN} / \mathrm{g} \text { de } \\
\text { solo } \mathrm{seco} / \mathrm{h})\end{array}$ \\
\hline Floresta isolada & $22,93 \mathrm{~b}$ & $679,89 \mathrm{~b}$ \\
Floresta integrada & $37,02 \mathrm{a}$ & $1.682,98 \mathrm{a}$ \\
Milho & $0,15 \mathrm{~d}$ & $270,27 \mathrm{c}$ \\
Eucalipto & $15,74 \mathrm{c}$ & $154,24 \mathrm{c}$ \\
Pasto & $13,83 \mathrm{c}$ & $1.747,07 \mathrm{a}$ \\
\hline $\mathrm{CV}(\%)$ & 15,09 & 10,89 \\
\hline &
\end{tabular}

vezes menor que o maior valor observado. Em solos de Iowa (Tabatabai \& Singh, 1976), a atividade dessa enzima variou de 136 a 874, com uma média de 304 nmoles de $\mathrm{SCN}^{-} / \mathrm{g}$ de solo seco/h. Embora nos solos de floresta integrada e de pastagem a atividade da rodanase tenha sido bem superior, a média dos dados foi inferior à apresentada nos solos de Iowa. Lawrence et al. (1988) verificaram que a atividade da rodanase aumentou, como resultado da aplicação de $\mathrm{S}^{0}$, e correlacionou-se com o aumento das populações de microrganismos autotróficos e heterotróficos $\mathrm{S}_{2} \mathrm{O}_{3}{ }^{2-}$-oxidantes. No presente trabalho, nenhuma correlação foi encontrada com os microrganismos analisados. Contudo, tais resultados indicam que existe um potencial de oxidação enzimática de tiossulfato a sulfito, uma vez que a rodanase correlacionou com o $\mathrm{S}$ total $\left(\mathrm{R}=0,89^{* *}\right)$ e o orgânico $\left(\mathrm{R}=0,90^{* *}\right)$ e foi dependente de uma atividade biológica heterotrófica, pois correlacionou com o C orgâ$\operatorname{nico}$ total $\left(\mathrm{R}=0,41^{* *}\right)$.

\section{Conclusões}

1. Os solos de pastagem, floresta integrada e eucalipto estimulam o crescimento das populações de microrganismos autótrofos $\mathrm{S}^{0}$-oxidantes, e o de floresta integrada, os heterotróficos $\mathrm{S}_{2} \mathrm{O}_{3}{ }^{2-}$-oxidantes.

2. As atividades da arilsulfatase e da rodanase aumentam de acordo com o aumento dos conteúdos de C orgânico, S total e S orgânico.

\section{Agradecimentos}

À Fapesp, pela concessão de bolsa de estudos a um dos autores.

\section{Referências}

ACQUAYE, D. K.; KANG, B. T. Sulfur status and forms in some surface soils of Ghana. Soil Science, Baltimore, v. 144, p. $43-52,1987$.

BARDSLEY, C. E.; LANCASTER, J. D. Sulfur. In: BLACK, C. A.; EVANS, D. D.; ENSMINGER, L. E.; WHITE, J. L.; CLARK, F. E. (Ed.). Methods of soil analysis. Madison: American Society of Agronomy, 1965. pt. 2, p. 1103-1116.

BUNT, J. S.; ROVIRA, A. D. Microbiological studies of some subantartic soils. Journal of Soil Science, Oxford, v. 6 , p. 119-128, 1955. 
CASTELLANO, S. D.; DICK, R. P. Cropping and sulfur fertilization influence on sulfur transformations in soil. Soil Science Society of America Journal, Madison, v. 54, p. 114-121, 1990.

CHAPMAN, S. J. Powdered elemental sulfur: oxidation rate, temperature dependence and modeling. Nutrient Cycling in Agroecosystems, Dordrecht, v. 47, 19-28, 1997.

CHAPMAN, S. J. Thiobacillus populations in some agricultural soils. Soil Biology \& Biochemistry, Oxford, v. 22 , p. 479-482, 1990.

DODGSON, K. S.; WHITE, G. F.; FITZGERALD, J. W. Sulfatases of microbial origin. Boca Raton: CRC Press, v. 1, 1982.

ERIKSEN, J.; MORTENSEN, J. V.; NIELSEN, J. D.; NIELSEN, N. E. Sulphur mineralization in five Danish soils as measured by plant uptake in a pot experiment. Agriculture, Ecosystems and Environment, Amsterdam, v. 56, p. 43-51, 1995.

FARREL, R. E.; GUPTA, V. V. S. R.; GERMIDA, J. J. Effects of cultivation on the activity and kinetics of arylsulfatase in Saskatchewan soils. Soil Biology \& Biochemistry, Oxford, v. 26, p. 1033-1040, 1994.

GANESHAMURTHY, A. N.; NIELSEN, N. E. Arylsulphatase and the biochemical mineralization of soil organic sulphur. Soil Biology \& Biochemistry, Oxford, v. 22, p. 1163-1165, 1990.

GUPTA, V. V. S. R.; FARRELL, R. E.; GERMIDA, J. J. Activity of arylsulfatase in Saskatchewan soils. Canadian Journal of Soil Science, Ottawa, v. 73, p. 341-347, 1993.

KANG, H.; FREEMAN, C. Phosphatase and arylsulphatase activities in wetland soil: annual variation and controlling factors. Soil Biology \& Biochemistry, Oxford, v. 31, p. 449-454, 1998.

KELLY, D. P.; SHERGILL, J. K.; LU, W. P.; WOOD, A. P. Oxidative metabolism of inorganic sulfur compounds by bacteria. Antonie van Leeuwenhoek, Dordrecht, v. 71, p. 95-107, 1997.

KLOSE, S.; TABATABAI, M. A. Arylsulfatase activity of microbial biomass in soils. Soil Science Society of America Journal, Madison, v. 63, p. 569-574, 1999.

LAWRENCE, R. J.; GERMIDA, J. J. Microbial and chemical characteristics of elemental sulfur beads in agricultural soils. Soil Biology \& Biochemistry, Oxford, v. 23, p. 617-622, 1991.

LAWRENCE, R. J.; GERMIDA, J. J. Most-probablenumber procedure to enumerate $S^{\circ}$-oxidizing, thiosulfate producing heterotrophs in soil. Soil Biology \& Biochemistry, Oxford, v. 20, p. 577-578, 1988.
LAWRENCE, J. R.; GUPTA, V. V. S. R.; GERMIDA, J. J. Impact of elemental sulfur fertilization on agricultural soils. II. Effects on sulfur-oxidizing populations and oxidation rates. Canadian Journal of Soil Science, Ottawa, v. 68, p. 475-483, 1988.

LENS, P.; TICHY, R.; POL, L. H. Sulfur cycle. In: LEDERBERG, J. (Ed.). Encyclopedia of microbiology. 2. ed. San Diego: Academic, 2000. v. 4, p. 495-505.

NAHAS, E.; DELFINO, J. H.; ASSIS, L. C. Atividade microbiana e propriedades bioquímicas do solo resultantes da aplicação de gesso agrícola na cultura do repolho. Scientia Agricola, Piracicaba, v. 54, p. 160-166, 1997.

NOR, Y. M.; TABATABAI, M. A. Colorimetric determination of microgram quantities of thiosulfate and tetrathionate. Analytical Letters, New York, v. 8, p. 537547, 1975.

ROSS, D. J.; SPEIR, T. W.; KETTLES, H. A.; MacKAY, A. D. Soil microbial biomass, $\mathrm{C}$ and $\mathrm{N}$ mineralization and enzyme activities in a hill pasture: influence of season and slow-release P and S fertilizer. Soil Biology \& Biochemistry, Oxford, v. 27, p. 1431-1443, 1995.

SHAN, X. Q.; CHEN, B.; ZHANG T. H.; LI, F. L.; WEN, B.; QIAN, J. Relationship between sulfur speciation in soil and plant availability. Science of the Total Environment, Amsterdam, v. 199, p. 237-246, 1997.

SIMS, J. R.; HABY, V. A. Simplified colorimetric determination of soil organic matter. Soil Science, Baltimore, v. 112, p. 137-141, 1971.

TABATABAI, M. A.; BREMNER, J. M. Arylsulfatase activity of soils. Soil Science Society of America Proceedings, Madison, v. 34, p. 225-229, 1970.

TABATABAI, M. A.; BREMNER, J. M. Distribution of total and available sulfur in selected soils and soil profiles. Agronomy Journal, Madison, v. 64, p. 40-44, 1972.

TABATABAI, M. A.; SINGH, B. B. Rhodanese activity in soils. Soil Science Society of America Journal, Madison, v. 40, p. 381-385, 1976.

TATE, R. L. The sulfur and related biogeochemical cycles. In: TATE, R. L. (Ed.). Soil microbiology. New York: J. Willey, 1995. p. 359-373.

VANCE, E. D.; BROOKES, P. C.; JENKINSON, D. S. An extraction method for measuring soil microbial biomass C. Soil Biology \& Biochemistry, Oxford, v. 19, p. 703-707, 1987.

VITOLINS, M. I.; SWABY, R. J. Activity of sulphuroxidizing microorganisms in some Australian soils. Australian Journal of Soil Research, East Melbourne, v. 7, p. 171-183, 1969. 